\title{
Tissue Engineering Approaches to Modulate the Inflammatory Milieu following Spinal Cord Injury
}

\author{
Courtney M. Dumont ${ }^{a}$ Daniel J. Margull ${ }^{a}$ c Lonnie D. Shea ${ }^{a, b}$ \\ Departments of ${ }^{\mathrm{a} B i o m e d i c a l ~ E n g i n e e r i n g ~ a n d ~}{ }^{\mathrm{b}}$ Chemical Engineering, University of Michigan, Ann Arbor, Mich., and \\ 'Department of Biomedical Engineering, Northwestern University, Evanston, III., USA
}

\section{Key Words}

Spinal cord injury · Inflammation · Tissue engineering

\begin{abstract}
Tissue engineering strategies have shown promise in promoting healing and regeneration after spinal cord injury $(\mathrm{SCl})$; however, these strategies are limited by inflammation and the immune response. Infiltration of cells of the innate and adaptive immune responses and the inflammation that follows cause secondary damage adjacent to the injury, increased scarring, and a potently inhibitory environment for the regeneration of damaged neurons. While the inflammation that ensues is typically associated with limited regeneration, the immune response is a crucial element in the closing of the blood-brain barrier, minimizing the spread of injury, and initiating healing. This review summarizes the strategies that have been developed to modulate the immune response towards an anti-inflammatory environment that is permissive to the regeneration of neurons, glia, and parenchyma. We focus on the use of biomaterials, biologically active molecules, gene therapy, nanoparticles, and stem cells to modulate the immune response, and illustrate concepts for future therapies. Current clinical treatments for $\mathrm{SCl}$ are limited to systemic hypothermia or methylpredniso-
\end{abstract}

\section{KARGER}

(๑) 2016 S. Karger AG, Basel

E-Mail karger@karger.com

www.karger.com/cto lone, which both act by systemically mitigating the effects of immune response but have marginal efficacy. Herein, we discuss emerging research strategies to further enhance these clinical treatments by directly targeting specific aspects of the immune response.

(c) 2016 S. Karger AG, Basel

\section{Introduction}

Paralysis due to spinal cord injury (SCI) has long-lasting socioeconomic impacts, and results in profound physical deficits due to limited treatment options. Treatments for SCI have minimal efficacy due to limited regeneration in the spinal cord, which results from a number of factors such as the intrinsic potential of the neurons and a nonpermissive environment (e.g. glial scar) that develops from the highly inflammatory milieu generated by local and infiltrating leukocytes. In an effort to address these limitations to nerve regeneration following SCI, tissue engineering approaches are being employed, such as scaffolds to guide regenerating axons and limit leukocyte infiltration, gene and drug delivery techniques to pro-

C.M.D. and D.J.M. contributed equally to this work.

Lonnie D. Shea

Department of Chemical Engineering, University of Michigan

1119 Carl A. Gerstacker Building, 2200 Bonisteel Boulevard

Ann Arbor, MI 48109 (USA)

E-Mail ldshea@umich.edu 


\begin{tabular}{ll}
\hline Abbreviations used in this paper \\
\hline AAV & adeno-associated virus \\
BDNF & $\begin{array}{l}\text { brain-derived neurotrophic factor } \\
\text { chemokine C-C ligand }\end{array}$ \\
CCL & chondroitinase ABC \\
CNAB & central nervous system \\
CSPG & chondroitin sulfate proteoglycan \\
EAE & experimental autoimmune encephalomyelitis \\
ECM & extracellular matrix \\
FBGCs & foreign body giant cells \\
G-CSF & granulocyte colony-stimulating factor \\
GM-CSF & granulocyte macrophage colony-stimulating factor \\
HGF & hepatocyte growth factor \\
HSV & herpes simplex virus \\
IL & interleukin \\
MHC & major histocompatibility complex \\
MMP & matrix metallopeptidase \\
MSCs & mesenchymal stem cells \\
NSC & neural stem cell \\
PCL & polycaprolactone \\
PEG & poly(ethylene glycol) \\
PLA & polylactic acid \\
PLG & poly(lactide-co-glycolide) \\
PMMA & poly(2-hydroxyethyl methacralate) \\
ROS & reactive oxygen species \\
SCI & spinal cord injury \\
TGF- $\beta$ & transforming growth factor beta \\
TNF- $\alpha$ & tumor necrosis factor alpha \\
\hline &
\end{tabular}

mote a less inflammatory milieu, and cell-mediated therapies to promote alternatively activated immune cell populations that support regeneration. This review will highlight therapeutic strategies that can shift the injury microenvironment from highly inflammatory towards a more anti-inflammatory milieu to facilitate regeneration of the injured nerve tissue.

An understanding of the underlying biology has contributed to the development of strategies to modulate the inflammatory response that ensues after SCI. Figure 1 summarizes the peak infiltration time for each cell population infiltrating the injury throughout the acute, subacute, and chronic inflammatory phases in a mouse SCI model. Furthermore, the figure indicates the duration of efficacy for potential therapies, and will be discussed in greater detail as they become relevant. Immediately following SCI, astrocytes and microglia become activated and secrete cytokines that initiate the recruitment of leukocytes. The first leukocytes to infiltrate the injured tissue as part of the innate immune response are neutrophils, which are followed by monocytes that mature into macrophages or dendritic cells upon entering the tissue. Neu- trophils and macrophages are essential for preventing infection at the injury by producing reactive oxygen species (ROS) that kill foreign pathogens. Macrophages in particular phagocytose foreign antigens and cellular debris left behind by necrotic or apoptotic cells, including myelin debris which contains inhibitory proteins that prevent axons from regenerating [Filbin, 2003; Yiu and $\mathrm{He}$, 2006]. In addition to ROS, macrophages and neutrophils produce a wide array of inflammatory cytokines such as interleukin (IL)-1, IL-6, and tumor necrosis factor alpha (TNF- $\alpha$ ), which induce the apoptosis of neurons and oligodendrocytes, resulting in secondary damage. These cytokines also cause astrocytes to undergo astrogliosis, a process that involves aberrant morphology and proliferation in an effort to limit excitotoxicity and oxidative stress followed by the development of the glial scar [Klusman and Schwab, 1997]. Glial scar formation is integral for the closing of the blood-brain barrier, but is largely composed of highly neuroinhibitory chondroitin sulfate proteoglycans (CSPGs) [Fitch et al., 1999; Busch and Silver, 2007]. T cells are the last of the immune cells to infiltrate the tissue, and they target antigens remaining within the injury. The inflammatory cascade that ensues after SCI in humans and rats results in cavitation at the epicenter of the injury that is associated with reduced factors, such as laminin, matrix metalloproteinase (MMP)-1, and vascular endothelial growth factor A [Surey et al., 2014]. Finally, in the event of foreign material entering the spinal cord either during injury or implantation of a biomaterial, foreign body giant cells (FBGCs) may form via macrophage fusion, though this is poorly characterized in the spinal cord. The contribution of each of these leukocyte populations has generally been considered injurious to regeneration, though few studies have investigated their impact or modulation.

Although the immune response is largely responsible for the creation of an unfavorable environment for tissue regeneration, the initial inflammatory response is important in initiating closing of the blood-brain barrier, clearing debris, and preventing infection [Donnelly and Popovich, 2008]. While initial inflammation is essential for recovery from injury, the persistence of neutrophils and macrophages into the chronic phase of injury is believed to worsen outcomes [Waxman, 1989; Beck et al., 2010]. In peripheral tissues, a shift in macrophage phenotype along a spectrum of activation states from inflammatory (M1 or classically activated) to anti-inflammatory (M2 or alternatively activated) is typically observed, and this shift is essential for the resolution of the immune response [Mosser, 2003; Murray and Wynn, 2011; Sindrilaru et al., 


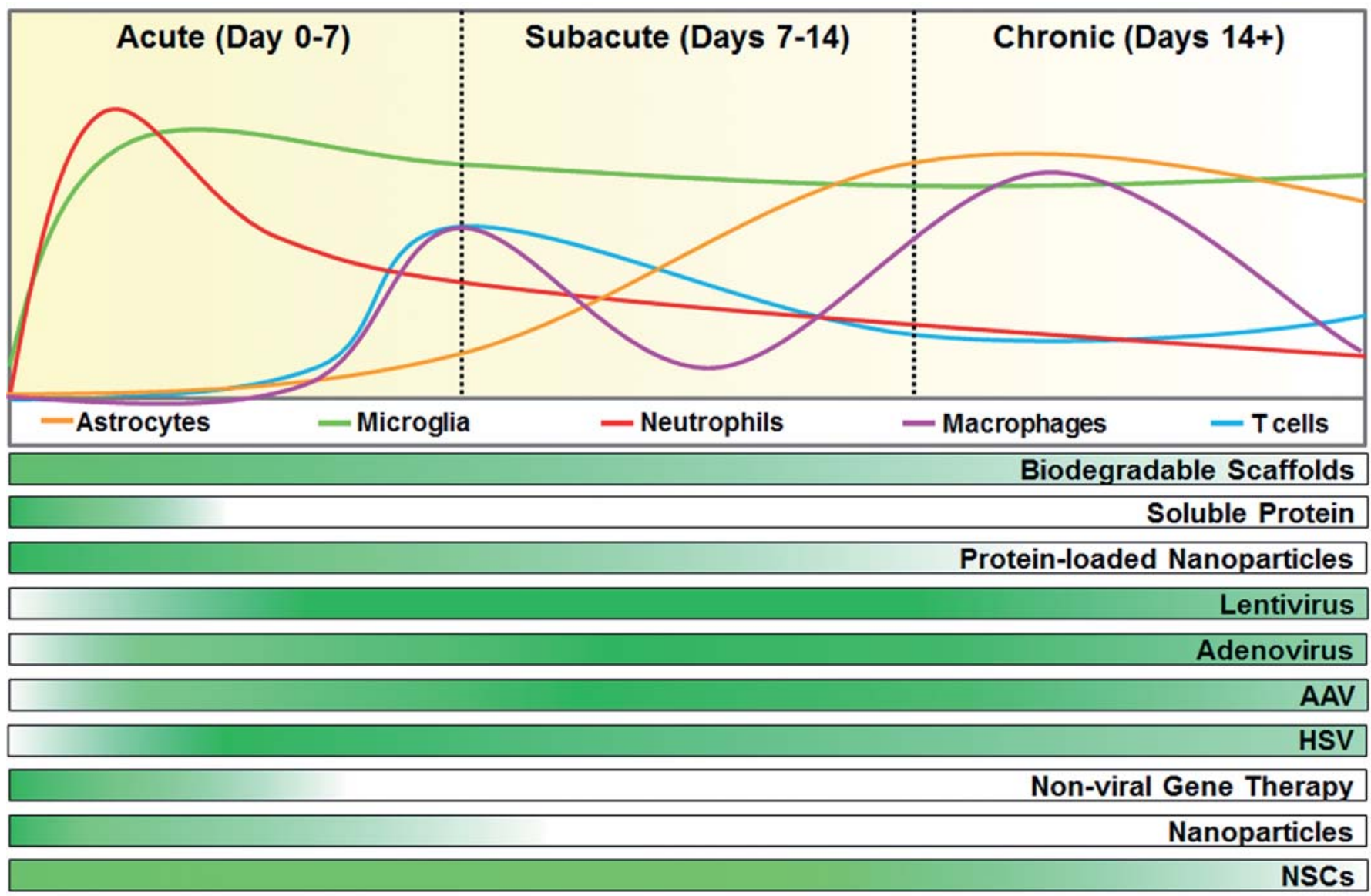

Fig. 1. Design considerations of the onset and duration of immunomodulatory benefits of therapeutics to correspond with specific phases of inflammation after SCI can target specific inflammatory cell populations. The local inflammatory cell proliferation and leukocyte infiltration fluctuates within the spinal cord after injury, as indicated by the relative peaks and valleys for each population over time. In the mouse model of SCI, neutrophil infiltration peaks within the first $24 \mathrm{~h}$ of the acute phase of inflammation. Microglia numbers rapidly increase during the acute phase and remain elevated into late stages of inflammation. Macrophages and $\mathrm{T}$ cells attain peak infiltration after 1 week and initiate the transition from acute to subacute phases of inflammation. Macrophages undergo a second population expansion during chronic inflammation.

2011]. However, this transition does not occur on a sufficient scale after SCI with M1 macrophages chronically causing the degeneration of axons and inflammation [Popovich et al., 2002; Horn et al., 2008; Busch et al., 2009; Kigerl et al., 2009; Kitayama et al., 2011; Pruss et al., 2011]. Similarly, cytotoxic T cells that target myelin for removal are abundant during chronic SCI resulting in trauma-induced autoimmunity, conversely therapeutics that recruit regulatory $\mathrm{T}$ cells can be used to modulate the $\mathrm{T}$ cell
While astrocytes are present throughout inflammation, astrogliosis peaks between 7 and 14 days after injury. The efficacy of a variety of therapeutics throughout the phases of inflammation assuming immediate delivery to the spinal cord after injury is demonstrated below the cell infiltration timeline. Darker green color indicates greater immunomodulatory potential, while lighter colors indicate the therapeutic benefits are diminishing. Timelines for cell infiltration and therapeutic benefits were obtained from the following sources: Popovich et al. [1997]; Blits et al. [2003]; Blits and Bunge [2006]; Donnelly and Popovich [2008]; Nguyen et al. [2011]; Wang et al. [2012]; Thomas and Shea [2013]; Gao et al. [2014]; Papa et al. [2014].

response to favor regeneration [Jones, 2014]. Additionally, depletion of potentially harmful leukocyte populations has resulted in seemingly contradictory results, ranging from improved to a worsening of regenerative and functional outcomes following SCI. LY6G/Gr-1+ neutrophil depletion leads to higher ROS in an SCI lesion and impaired functional outcomes [Stirling et al., 2009]. In contrast, reducing neutrophil and macrophage infiltration using CD11d/CD18 antibodies reduces ROS and 
Table 1. Selection of appropriate topographical, mechanical, and chemical design parameters for biomaterial scaffolds can support antiinflammatory cell phenotypes and downstream effects promoting a regenerative milieu following SCI

\begin{tabular}{|c|c|c|}
\hline Regenerative consequence & Design parameters & References \\
\hline $\begin{array}{l}\text { Reduced infiltration and } \\
\text { attachment }\end{array}$ & $\begin{array}{l}\text { Porosity, nanotopography, } \\
\text { hydrophobicity }\end{array}$ & $\begin{array}{l}\text { Dadsetan et al. [2008]; Hezi-Yamit et al. [2009]; Lee et al. [2011]; } \\
\text { Thomas et al. [2013] }\end{array}$ \\
\hline Improved integration & Porosity & Dadsetan et al. [2008]; Thomas et al. [2013]; Almeida et al. [2014] \\
\hline Increased M2 polarization & $\begin{array}{l}\text { Porosity, grooves, } \\
\text { nanotopography, low stiffness }\end{array}$ & $\begin{array}{l}\text { Lee et al. [2011]; Saino et al. [2011]; Blakney et al. [2012]; } \\
\text { McWhorter et al. [2013]; Almeida et al. [2014]; Sussman et al. } \\
\text { [2014] }\end{array}$ \\
\hline Reduced FBGCs & $\begin{array}{l}\text { Porosity, aligned fibers, } \\
\text { hydrophobicity, low stiffness }\end{array}$ & $\begin{array}{l}\text { Jones et al. [2007]; Cao et al. [2010]; Blakney et al. [2012]; } \\
\text { Sussman et al. [2014] }\end{array}$ \\
\hline Reduced glial scar thickness & General biomaterials, porosity & Wong et al. [2008]; Yang et al. [2009]; Khaing et al. [2011] \\
\hline Limited T cells & $\begin{array}{l}\text { Anti-Fas antibody incorporation, } \\
\text { nanotopography }\end{array}$ & Hume and Anseth [2010]; Kwon et al. [2012] \\
\hline
\end{tabular}

apoptosis, resulting in functional improvements [Saville et al., 2004; Bao et al., 2005; Geremia et al., 2012]. Macrophage depletion with dichloromethylene bisphosphonate improved partial hind limb recovery and tissue repair [Popovich et al., 1999], while CD11c+ monocyte/macrophage depletion reduced functional outcomes [Shechter et al., 2009]. These seemingly contradictory results further support the idea that more sophisticated strategies that promote shifts within immune cell populations towards anti-inflammatory phenotypes, such as M2 macrophages and regulatory $\mathrm{T}$ cells, will prove more advantageous to regeneration than simply eliminating select leukocyte populations. Additionally, there may be unintended consequences when depleting immune cell populations, particularly the increased risk of infection or disease due to being systemically immunocompromised. The following sections will focus on strategies that shift the inflammatory response towards anti-inflammatory cell phenotypes, such as M2 macrophages and regulatory $\mathrm{T}$ cells, which limit secondary injury and foster regeneration of the injured spinal cord.

\section{Biomaterials}

\section{Scaffolds}

Neurons in the adult central nervous system (CNS) maintain a capacity for regeneration that is limited by an intensely neuroinhibitory microenvironment that limits endogenous regeneration. This response is most clearly demonstrated by substantial regeneration of CNS axons through peripheral nerve grafts [David and Aguayo, 1981; Cote et al., 2011]. Biomaterial approaches to SCI have been designed to replicate the salient features of these peripheral nerve grafts: an architecture that simultaneously provides physical guidance, promotes cell infiltration to secrete regeneration factors, and mitigates inhibitory byproducts of primary and secondary damage. Biomaterial scaffolds have demonstrated the ability to effectively provide physical guidance and support cell infiltration. Biomaterial interactions with immune cells, however, are highly complex and affected by both the physical and chemical properties of scaffolds in ways that may be beneficial and/or deleterious, and are described below. The creation of an ideal immunomodulatory scaffold for SCI has been a formidable challenge, and the following parameters and features are essential considerations for design and are summarized in table 1.

The spinal cord is a complicated structure with a large number of ascending and descending neural tracts that connect specific brain structures to precise locations on the body. When approaching neural regrowth after SCI, to augment the functional improvements associated with plasticity it is imperative to maintain the spatial organization of the spinal cord in order to increase the likelihood that a regenerating axon will find a suitable target after regenerating past the injury site [Weidner and Tuszynski, 2002]. For minor contusive injuries, strategies such as cellular grafts that reduce secondary injury, facilitate sparing of intact tracts, and promote regrowth may be the best option [Haggerty and Oudega, 2013]. However, for more severe contusions and penetrating SCI, even if the tissue 
architecture is initially preserved, secondary damage results in cavitation, atrophic parenchyma, and glial scarring. These scenarios require a biomaterial bridge that provides a permissive pathway for regenerating neurons to bypass or cross the injury site [Straley et al., 2010]. Therefore, in order to bridge the injury site and give neurons the best chance of reaching appropriate targets, the optimal biomaterial scaffold design for SCI will most likely incorporate either channels or a guidance system parallel to the spinal cord tracts [Sakiyama-Elbert et al., 2012].

While a conduit that guides neurons seems to be a logical scaffold design, direct experimental evidence to verify this claim is sparse, as are studies on its role in modulating the immune response. In 2008, Wong et al. [2008] completed the most comprehensive analysis to date that tests how overall scaffold design facilitates the regrowth of sensory and motor tracts. Using salt-leached porous polycaprolactone (PCL) cast in cylinder, tube, channel, and open path configurations, they observed that open path designs were superior to all other designs in being permissive to axon regeneration into the injury and reducing the extent of secondary damage and glial scarring. Despite the reported result, the authors noted that the regenerating nerves could have been either regenerating white matter tracts or nerve roots entering from the side. Additionally, the lack of regeneration they report from the multichannel design are in direct contrast to other reports [Olson et al., 2009; Tuinstra et al., 2014].

When designing biomaterial scaffolds for the spinal cord, the mechanical properties of scaffolds and the changes that occur to them during degradation are essential considerations. Scaffolds must have appropriately matched stiffness while still being strong enough not to collapse and cause obstruction to nerve regeneration. When implanted in vivo, degradation, repetitive compression from movement, and immune cell-related breakdown and clearance can all reduce the lifetime of biomaterial scaffolds and can cause graft failure if it happens too soon [Belkas et al., 2005]. On the other hand, appropriately timed degradation such that the biomaterial can be replaced by extracellular matrix (ECM) deposition can result in axon bundles surviving completed degradation of the biomaterial [Tuinstra et al., 2014]. Strategies to alter scaffold mechanical properties may also alter wound healing and the immune response. For example, poly(ethylene glycol) (PEG) hydrogels with lower stiffness lead to reduced macrophage activation and a less severe foreign body response [Blakney et al., 2012].

The macroarchitecture of biomaterial scaffolds facilitates the wound-healing process by acting as a framework for cell infiltration and remodeling and, in doing so, altering the immune response. Cellular infiltration within a porous material network allows for the integration of host tissue that reduces cavitation as well as the glial scar. While mice typically exhibit minimal cavitation in SCI, larger animals, such as rats, exhibit prominent cyst formation at the injury epicenter, similar to what occurs in human SCI. In contrast to the macrophage-filled cysts in rats, mouse lesion sites are rich in the ECM proteins laminin and collagen, proangiogenic factors, and pro-woundhealing factors [Surey et al., 2014]. These characteristics are associated with delayed T cell entry and a lack of dendritic cell infiltration in mice relative to rats [Sroga et al., 2003]. Although the mechanism is incomplete, biomaterial scaffolds and hydrogels reduce the thickness of the glial scar while concomitantly reducing the macrophage population [Teng et al., 2002; Yang et al., 2009]. Whether this effect results from space filling or a material property is unclear, but the introduction of a scaffold profoundly affects immune cell infiltration while replacing cavitation and the thick glial scar with regenerating tissue as observed by the absence of significant cyst formation after spinal cord bridge implantation in highly porous or open designs [Wong et al., 2008; De Laporte et al., 2009b].

In order to promote and support regeneration, biomaterial scaffolds must be permissive to cellular infiltration, biomolecule diffusion, and vascular infiltration at the microstructural level. These properties are achieved by utilizing pores, grooves, or polymer fibers and can have profound effects on the immune response. Porosity allows for scaffold vascularization, alters cell migration and phenotype into and around the scaffold, and improves implant stability at the tissue-implant interface [Dadsetan et al., 2008; Thomas et al., 2013]. The pore size has been shown to alter macrophage phenotype in a size-dependent fashion with $160-\mu \mathrm{m}$ pores pushing the macrophage population towards an M2 phenotype in comparison to $34-\mu \mathrm{m}$ pores in subcutaneous implants [Sussman et al., 2014]. While the smaller pores in this example supported greater vascular infiltration, both pore sizes reduced the FBGC response and promoted healing. Whether this effect would be observed in the spinal cord is unknown; however, design parameters that promote the formation of M2 macrophages and resolution of inflammation are essential for SCI. Pore geometry has been observed to alter the macrophage phenotype with diagonal geometries resulting in less FBGCs and elongated (M2) macrophages in the context of 3D printed chitosan and polylactic acid (PLA) scaffolds [Almeida et al., 2014]. Grooves have also been shown to interact with macrophages in particular.
Dumont/Margul/Shea 
Recently, McWhorter et al. [2013] demonstrated that cell elongation with grooves can induce M2 phenotypic marker expression and enhance the effects of M2-inducing cytokines, though this has not yet been demonstrated in vivo. In a similar manner, aligned PCL electrospun nanofibers minimize the immune response by reducing the thickness of the fibrous capsule surrounding the scaffold, reducing monocyte adhesion, and increasing cell infiltration compared to random fiber and films [Cao et al., 2010]. Additionally, the aligned orientation of fibronectin-coated poly-L-lactic acid fibers has been shown to enhance GLT-1-mediated glutamate uptake and astrocyte migration in vitro [Zuidema et al., 2014]. Finally, nanofibrous scaffolds result in reduced macrophage-mediated proinflammatory cytokine release, including granulocyte colony-stimulating factor (G-CSF), chemokine C-C ligand (CCL)-5, and TNF- $\alpha$ relative to scaffolds made of micron-scale fibers [Saino et al., 2011].

Though nanotopography effects can be challenging to isolate from changes in surface chemistry as they can be interrelated, both nanoscale surface features and chemistry can alter the function and migration patterns of immune cells. Few studies have investigated the interactions between nanotopography and the immune response; however, both the innate and adaptive immune responses have been demonstrated to be affected. On nanostructured titanium, macrophage motility was restricted, and reduced M1 macrophage polarization on titanium substrates was observed [Lee et al., 2011]. In a similar way, nanopatterned (grooved) polyurethane acrylate surfaces caused directional topography-guided migration of $\mathrm{T}$ cells [Kwon et al., 2012]. The effects of surface chemistry have been studied in much greater detail; in particular, the relationship between the chemical properties of a surface and protein adsorption has been thoroughly characterized as protein adsorption interacts and directly activates immune cells. Immediately following blood-material contact, a layer of protein adsorbs to the surface resulting in the formation of a blood clot that recruits the cells of the innate immune system to the injury. The severity of the ensuing inflammation is highly dependent on the biochemical properties of the material and how it denatures adsorbed proteins. Natural materials such as collagen [De Laporte et al., 2009a], hyaluronic acid [Kang et al., 2009], and fibrin [Taylor et al., 2006] are often considered biocompatible given that they are naturally found in the ECM of many tissues, including the spinal cord, but they can be immunogenic and their properties can change substantially during processing. Synthetic materials such as poly(lactide-co-glycolide) (PLG) [Tuinstra et al., 2014],
PEG [Luo and Shi, 2007], and poly(2-hydroxyethyl methacralate) (PMMA) [Hejcl et al., 2008], though not native to the spinal cord, also have minimal immune responses that can be further modulated. The degree of hydrophilicity/hydrophobicity is particularly important as hydrophobic materials are more likely to denature adsorbed proteins and are associated with decreased monocyte adhesion [Hezi-Yamit et al., 2009] as well as decreased macrophage adhesion and FBGC formation in vitro [Jones et al., 2007].

\section{Particle Delivery}

Nanoparticles have been used to deliver a therapeutic to the injured spinal cord; however, a growing number of researchers are investigating the inherent ability of polymeric particles to module the immune cell response. Local delivery of both PMMA and PCL-PEG composite nanoparticles have been shown to be selectively internalized by proinflammatory macrophages and microglia following SCI [Papa et al., 2013, 2014]. Similarly, monocyte uptake of PLG and polystyrene nanoparticles containing antigen peptides has been shown to induce antigen-specific tolerance for the prevention and treatment of experimental autoimmune encephalomyelitis (EAE) - the murine multiple sclerosis model [Getts et al., 2012; Hunter et al., 2014; Maldonado et al., 2015]. Tolerance was dependent on particle uptake by the MARCO (macrophage receptor with collagenous structures) scavenger receptor, in part due to the anionically charged surface of the nanoparticles [Kanno et al., 2007]. As uptake of these particles was independent of the antigen, it is likely that naked PLG and polystyrene nanoparticles can also be used to target and modify macrophages following SCI. Additionally, nanoparticles with antigen capable of inducing myelin-specific tolerance could be used to alleviate the chronic inflammatory phase of SCI, which is characterized by unfettered demyelination comparable to EAE models [Jones, 2014]. Other particles, including iron oxide [Pal et al., 2013], gold [Hutter et al., 2010], and quantum dots [Minami et al., 2012; Moquin et al., 2015], have also been used to target microglia and reduce inflammation using in vitro models.

\section{Therapeutic Delivery Considerations}

Local and systemic injection of biologically active molecules, including protein, gene, and cellular therapies, can be used to modulate the immune response at the site of injury. Systemic injection of these molecules can redirect immune cell trafficking and promote anti-inflammatory immune phenotypes throughout the body and within the 
spinal cord. Unfortunately, many molecules used have pleotropic effects and can cause off-target effects. Additionally, a larger amount of the protein needs to be delivered systemically to elicit changes in inflammation within the spinal cord. Moreover, while the blood-brain barrier is temporarily open during the acute stage of SCI, it begins to close after 3 days [Popovich et al., 1996; Whetstone et al., 2003], limiting the time window in which systemic treatments can be effective [Jeffery et al., 2009]. Local injection of these molecules with osmotic pumps directly into the cerebrospinal fluid can be utilized to avoid systemic side effects and limit the amount of protein needed, though osmotic pumps tend to clog, may require a second surgery for removal, and can cause further tissue damage [Jones and Tuszynski, 2001]. The use of direct injection methods, whether systemic or local, can exhibit limited protein bioactivity due to rapid degradation within hours to days depending on the molecule, thus limiting the therapeutic window.

Utilization of a delivery vehicle, such as scaffolds and nanoparticle carriers, for biologically active molecules can extend their bioactivity by providing protection from proteolysis that commonly affects unbound soluble proteins. Proteins or enzymes can be incorporated into a biomaterial, adsorbed onto the surface, or covalently bound to a material. Inclusion of proteins into hydrogels or polymeric scaffolds can be used to localize the proteins at the injury site to modulate the local astrocyte and microglia response, as well as that of the infiltrating leukocytes following injury [Hayashi et al., 2009; Wilems and Sakiyama-Elbert, 2015]. Protein-loaded scaffolds used in penetrating SCI models perform several functions by not only delivering proteins and increasing their bioavailability, but also filling the tissue void and reducing glial scar formation. Micro- and nanoparticles have been developed to deliver specific proteins to modulate immune cell infiltration and phenotype following SCI and can be used in both contusion and penetrating SCI models. Therapeutic proteins can be encapsulated within or incorporated throughout the particle depending on the desired release profile relative to leukocyte infiltration and the duration of bioactivity. Particles can be administered locally via the cerebrospinal fluid or by incorporation into a hydrogel. Alternatively, systemically administered particles can include a targeting peptide that will traffic the particles with the therapeutic to the site of inflammation [Ruoslahti, 2012]. This method allows for safer administration at a more easily accessible injection site outside the CNS but offers opportunities that mirror local delivery strategies. Encapsulation of the therapeutic is appropriate for sys- temically delivered particles as a precaution to limit pleotropic effects prior to arrival in the spinal cord. Zuidema et al. [2016] provide further information regarding nanoparticle design for therapeutic and diagnostic delivery to the CNS.

\section{Biologically Active Molecules}

Biologically active molecules, including matrix proteins, growth factors, cytokines, enzymes, and antibodies, have been utilized to reduce inflammation and promote regeneration after SCI. Nonbiologic pharmaceutical agents, such as methylprednisolone and dexamethasone, have been used to systemically suppress the immune response, and have been reviewed elsewhere [Ilinskaya and Dobrovolskaia, 2014]. Modulating the immune response to promote a more anti-inflammatory phenotype among immune cells at the site of SCI offers greater regenerative capacity than systemic immune suppression. This phenomenon has been documented with neutrophil and macrophage depletion studies that exacerbated damage after SCI, thus demonstrating the importance of the immune cells in promoting a microenvironment primed for regeneration [Shechter et al., 2009; Stirling et al., 2009]. To ensure a more regenerative immune cell phenotype, a number of local and systemic delivery strategies have been utilized to modulate the immune response with biologically active molecules. These molecules can be used to target specific events or cell populations within each phase of the inflammatory response with the goal of promoting an anti-inflammatory milieu, as the highly complex and precisely timed coordination of leukocytes and local cell populations that ensue after SCI are well documented. Delivering appropriately timed biologically active molecules that target one or more specific phase of inflammation after SCI can limit secondary damage and promote regeneration. While biologically active molecules hold promise in modulating the inflammatory milieu, these factors can degrade and rapidly reduce their bioavailability. These challenges can be addressed through the use of more robust molecules, inclusion of a delivery vehicle, or considerations of the timing and location of delivery that must be designed specifically for each protein. The following sections will explore therapeutic options for each phase of inflammation as well as an overview of considerations for delivery of these biologically active molecules. Table 2 summarizes the anti-inflammatory benefits and regenerative consequences garnered from proteins previously deliv-
58

Cells Tissues Organs 2015-16;202:52-66 DOI: $10.1159 / 000446646$
Dumont/Margul/Shea 
Table 2. An anti-inflammatory milieu that supports regeneration can be established through the delivery of proteins, genes, and cells to the spinal cord

\begin{tabular}{|c|c|c|}
\hline Regenerative consequence & Therapeutic intervention & References \\
\hline $\begin{array}{l}\text { Reduced infiltration and } \\
\text { recruitment }\end{array}$ & G-CSF, PPAR- $\gamma$, IL-33, MSCs & $\begin{array}{l}\text { Ifergan et al. [2006]; Lee et al. [2009]; Chu et al. [2014]; Pomeshchik et } \\
\text { al. [2015]; Watanabe et al. [2015] }\end{array}$ \\
\hline Increased M2 polarization & $\begin{array}{l}\text { IL-4, IL-10, IL-13, IL-33, } \\
\text { aFGF, galectin-1, G-CSF, } \\
\text { M-CSF, BDNF, chABC, } \\
\text { MSCs }\end{array}$ & $\begin{array}{l}\text { Vannier et al. [1992]; Bethea et al. [1999]; Martinez et al. [2008]; Zhou } \\
\text { et al. [2008]; Lee et al. [2010]; Kuo et al. [2011]; Nakajima et al. [2012]; } \\
\text { Guo et al. [2013]; Didangelos et al. [2014]; Fenn et al. [2014]; } \\
\text { Hamilton et al. [2014]; Gaudet et al. [2015]; Ji et al. [2015]; } \\
\text { Pomeshchik et al. [2015]; Watanabe et al. [2015] }\end{array}$ \\
\hline Reduced glial scar thickness & $\begin{array}{l}\text { IL-33, GM-CSF, C-CSF, } \\
\text { chABC, miR-21, miR-145, } \\
\text { HGF }\end{array}$ & $\begin{array}{l}\text { Bhalala et al. [2012]; Jeong et al. [2012]; Bartus et al. [2014]; Chung et } \\
\text { al. [2014]; Didangelos et al. [2014]; Pomeshchik et al. [2015]; Wang et } \\
\text { al. [2015] }\end{array}$ \\
\hline Increased regulatory $\mathrm{T}$ cells & HGF, EPO, IL-33, NSCs & $\begin{array}{l}\text { Yuan et al. [2008]; Wang et al. [2009]; Benkhoucha et al. [2010]; } \\
\text { Bonnamain et al. [2012]; Gao et al. [2014]; Pomeshchik et al. [2015] }\end{array}$ \\
\hline
\end{tabular}

ered to the injured spinal cord, as well as cellular and gene therapy approaches in subsequent sections of this review.

\section{Leukocyte Infiltration}

Limiting the initial infiltration of these cells in the acute phase of inflammation can reduce the secondary damage that occurs due to the highly inflammatory microenvironment caused by infiltrating immune cells. The systemic administration of G-CSF and statins has been shown to reduce vascular permeability through increased expression of aquaporin 4 and vascular endothelial growth factor [Ifergan et al., 2006; Chu et al., 2014]. Peroxisome proliferator-activated receptor gamma can also reduce vascular permeability through an inhibition of MMP-9 [Lee et al., 2009], which is responsible for the digestion of the vascular matrix [Noble et al., 2002]. These approaches offer a first defense against excessive proinflammatory leukocyte infiltration into the spinal cord. Subsequent use of biologically active molecules that promote an anti-inflammatory phenotype of the resident microglia and the infiltrating leukocytes would provide the next line of defense against secondary injury.

\section{Modulating Innate Immunity}

The innate immune response following $\mathrm{SCI}$ is characterized by the infiltration of neutrophils, monocytes, macrophages, and dendritic cells that release proinflam- matory cytokines that leads to secondary damage of the neurons and oligodendrocytes that survived the initial injury. It has been well documented that these leukocytes can undergo a phenotypic change resulting in a more anti-inflammatory phenotype that supports tissue regeneration. Typically, macrophages and microglia are targeted through the use of biologically active molecules to convert them from a proinflammatory M1 phenotype towards an anti-inflammatory M2 phenotype. A number of interleukins have been used to facilitate M2 polarization, including IL-4, IL-10, IL-13, and IL-33 [Bethea et al., 1999; Martinez et al., 2008; Lee et al., 2010; Fenn et al., 2014; Pomeshchik et al., 2015]. Similarly, acidic fibroblast growth factor, galectin-1, G-CSF, and myeloid colonystimulating factor have also been used to promote M2 macrophages and/or microglia following SCI, resulting in modest improvements to axon growth and functional recovery [Kuo et al., 2011; Guo et al., 2013; Hamilton et al., 2014; Gaudet et al., 2015]. G-CSF has also been shown to reduce oligodendrocyte death, suggesting that the reduction in proinflammatory cytokines leads to sparing of the remaining tissue. Interestingly, granulocyte macrophage colony-stimulating factor (GM-CSF) promotes M1 macrophage polarization and activation of dendritic cells, and leads to increased expression of brain-derived neurotrophic factor (BDNF) and early recovery of locomotor function after SCI [Hayashi et al., 2009; Hamilton et al., 2014]. It should be noted that BDNF can promote M2 
polarization, leading to increased expression of IL-10 and IL-13, with a subsequent decrease in the proinflammatory cytokines TNF- $\alpha$ and IL- $1 \beta$ [Ji et al., 2015]. The downstream signaling of BDNF leading to M2 polarization may provide a rational for how M1-promoting GMCSF can promote a regenerative milieu.

\section{Limiting Glial Scar Formation}

The primary endogenous means to spare the remaining nerve tissue is through the formation of the glial scar by astrocytes; however, if left unchecked, the glial scar can greatly exacerbate the amount of secondary damage. Delivery of IL-33, GM-CSF, and G-CSF can reduce glial scar formation although it is unclear as to whether this is through direct action on the astrocytes or due to the modulation of the leukocyte population leading to altered cytokine expression [Chung et al., 2014; Pomeshchik et al., 2015]. Astrocytes have been documented to produce IL33, GM-CSF, and G-CSF in an effort to reduce inflammation on their own, thus exogenous delivery may further reduce inflammation and the development of the glial scar [Aloisi et al., 1992; Yasuoka et al., 2011]. The astrocyte-derived CSPGs within the glial scar are thought to be the primary barrier to axonal elongation via physical blockade and a set of cellular and biochemical cues that instruct axonal growth cones to turn away or become dystrophic and stop regenerating [Cregg et al., 2014]. Chondroitinase $\mathrm{ABC}$ ( $\mathrm{chABC}$ ) can reduce the presence of the glial scar through enzymatic digestion of the CSPGs, but can also promote M2 macrophages that may reduce glial scar formation [Didangelos et al., 2014]. The inherent benefits of chABC delivery to the glial scar, including CSPG digestion, reduced cavitation, and altered macrophage polarization, can be further enhanced through the extended presence of the enzyme via lentiviral delivery of the chABC vector [Bartus et al., 2014].

\section{Modulating Adaptive Immunity}

The adaptive immune response consists of natural killer and lymphocyte populations. Many researchers have reported high levels of $\mathrm{T}$ cell activation towards myelin peptides during the chronic inflammation following SCI, as reviewed by Jones [2014]. This response is presumably due to the presence of a large amount of myelin debris following the primary and secondary damage that was phagocytosed by antigen-presenting cells, such as macrophages and dendritic cells, for presentation to T cells. Although the adaptive immune response has been infrequently targeted in SCI, IL-33 has been reported to limit $\mathrm{T}$ cell infiltration into the spinal cord [Pomeshchik et al.,
2015]. While effective, it is unclear if this cytokine acts directly on the $\mathrm{T}$ cells or if it is an artifact of the reduced oligodendrocyte death that accompanies IL-33 delivery to the spinal cord. Other therapeutic interventions aim to convert cytotoxic $\mathrm{T}$ cells to more regeneration of Th2 or regulatory $\mathrm{T}$ cell phenotypes to spare the remaining $\mathrm{my}$ elin and reduce the proinflammatory cytokines IL- 6 and interferon gamma. The presence of regulatory $\mathrm{T}$ cells would also confer the tolerance of foreign cells and biomaterials. Hepatocyte growth factor (HGF), erythropoietin, and IL-33 have been used independently to limit or modulate the aberrant T cell response [Yuan et al., 2008; Benkhoucha et al., 2010; Pomeshchik et al., 2015]. In addition to limiting inflammation, HGF and erythropoietin are potent chemoattractant factors for endogenous stem cell populations that could repair the damaged tissue [ $\mathrm{Li}$ et al., 2012; Merino et al., 2015]. In addition to cytokines, ligands or antibodies can be used to directly influence the adaptive immune response. Although it has not been used within the spinal cord, anti-Fas antibodies effectively promote the apoptosis of infiltrating cytotoxic $\mathrm{T}$ cells to prevent the rejection of implanted cells or scaffolds [Kim et al., 2006; Pearl-Yafe et al., 2007; Hume and Anseth, 2010].

\section{Gene Therapy}

While direct protein delivery can be effective for shortterm dosage, gene therapy provides an opportunity to achieve sustained expression. Gene therapy vectors can be broadly classified as viral and nonviral carriers. In order to substantially alter protein expression levels at biologically relevant concentrations, gene therapy must be efficient. Although great effort has been put into developing nonviral gene delivery methods, such as naked DNA or RNA, liposomes, and nanoparticles, nonviral gene delivery is limited in its ability to efficiently transfect cells, particularly in vivo. Viral vectors bypass these limitations by utilizing highly evolved mechanisms to incorporate their genetic material into cells, resulting in greater transduction efficiency and therefore expression levels. Moreover, some vectors, such as nonlentiviral retroviruses and adenovirus are unable to infect dividing cells, reducing their efficiency and utility. Cells - and neurons in particular - are not typically transduced by these types of viruses. For further discussion of gene therapy for SCI, see the review by Walthers and Seidlits [2015].

When approaching immunomodulation with gene therapy, there are a several important considerations
Dumont/Margul/Shea 
when choosing an appropriate vector. The timing of gene expression can be important when specifically targeting either the innate or adaptive immune response. An overview of the delayed onset and duration of gene expression is represented in figure 1. Nonviral therapy offers a lower level of expression, but does feature the quickest expression. The onset of transgene expression delivered by herpes simplex virus (HSV) or adenovirus is faster than other viral vectors, occurring within $24 \mathrm{~h}$ after administration [Blits and Bunge, 2006]. Lentivirus typically exhibits expression within $48 \mathrm{~h}$ after expression and maximal expression after 3-4 days [Thomas and Shea, 2013]. Finally, the onset of expression for adeno-associated virus (AAV) occurs by day 3 and peaks at day 7 [Boulis et al., 1999]. Vector size may also be an important consideration as AAV has a capacity of less than $5 \mathrm{~kb}$ of ssDNA, retrovirus can contain a maximum of $8-10 \mathrm{~kb}$ of ssRNA, and adenovirus and HSV have substantially higher transgene capacities. Finally, viral vectors are immunogenic on their own, which can complicate immunomodulation. AAV and lentivirus are generally considered to have a low level of transient immunogenicity, while adenovirus is highly inflammatory. For more information, see the review by Nayak and Herzog [2010].

\section{Leukocyte Response}

The role of neutrophils and lymphocytes in regeneration following SCI is not well understood, thus hindering the development of gene therapies to mechanistically target these cells. Conversely, macrophages have been frequently targeted with gene therapy for SCI as recent research has defined a spectrum of pro/anti-inflammatory phenotypes that active macrophages can exist within. IL-10, an anti-inflammatory cytokine, is known to inhibit the synthesis and release of proinflammatory mediators such as TNF- $\alpha$, IL- $1 \beta$, IL-6, IL- 8 , and IL-12, and has been shown to activate signaling pathways involved in neuronal survival and growth [Zhou et al., 2009b]. Lentiviral delivery of IL-10 to macrophages in vitro can sustain macrophage polarization towards an M2 phenotype, though this research has not yet been demonstrated in vivo in SCI [Boehler et al., 2014]. Delivery of IL-10 poliovirus replicons intramuscularly or intrathecally elevated IL-10 for 4 days with a peak at $24 \mathrm{~h}$ and improved functional injury when given immediately after injury [Jackson et al., 2005]. Intrathecal injection of HSV encoding IL-10 after a hemisection injury demonstrated improved axonal sparing, more functional recovery, and direct trophic support for neurons by IL-10 [Zhou et al., 2009a, b]. However, neither of these viral IL-10 studies investigated the effects on the immune response or how those effects alter regeneration. IL-4 is another prototypical anti-inflammatory cytokine that antagonizes and suppresses the effects of IL1, leading to M2 macrophage phenotypes [Vannier et al., 1992]. It has been shown that HSV-mediated expression of IL-4 can reduce neuropathic pain, but, like IL-10, it has not been clearly shown to promote M2 macrophagemediated healing in vivo [Hao et al., 2006]. Finally, $\mathrm{BDNF}$, a factor that provides neuroprotective benefits, promotes axon regeneration, and increases synaptic plasticity, has ancillary effects in that it promotes M2 macrophage polarization that may enhance neuroprotective effects and partially contribute to locomotor functional recovery after SCI [Ji et al., 2015].

\section{Astrogliosis and Wound Healing}

One of the most common approaches to mitigating astrogliosis is to target CSPG breakdown using chondroitinase, which proteolytically inactivates CSPGs such that they no longer inhibit axon elongation. This approach has been successful in reducing cavitation, preserving spinal neurons and axons, and improving sensorimotor function [Bartus et al., 2014]. Additionally, chondroitinase leads to IL-10 upregulation and a subsequent increase in M2 macrophages [Didangelos et al., 2014]. While breakdown of CSPGs is an effective way to remove one of the key barriers to regeneration, preventing deposition is expected to be more effective. To this end, several microRNAs have been identified. In particular, microRNA-21 plays a prominent role in the initial hypertrophic stage of astrogliosis that is essential for wound healing as opposed to the later hyperplasia responsible for progression of the glial scar. Overexpression of miR-21 attenuates hypertrophy and knockdown augments the hypertrophic phenotype even in chronic stages of SCI recovery [Bhalala et al., 2012]. Likewise, lentivirus-mediated pre-miRNA 145 delivery under the astrocyte-specific glial fibrillary acidic protein promoter reduced the astrocytic cell density at the lesion border of the injured spinal cord, reduced the size of astrocytes and the number of related cell processes, as well as cell proliferation and migration [Wang et al., 2015]. miR-145 likely exhibits global control over astrogliosis, in contrast to miR-21, which specifically controls the hypertrophic stage of astrogliosis. Finally, ex vivo gene therapy with HGF reduces transforming growth factor beta (TGF- $\beta$ ) levels, limits astrocytic scar formation and promotes axonal regeneration beyond the glial scar after SCI [Jeong et al., 2012]. 


\section{Stem Cell-Mediated Therapy}

Cell-mediated therapies hold promise in both modulating the immune response and repopulating the injury site. Stem cells are widely used following SCI, as they can directly contribute to nerve regeneration by repopulating the injury site and differentiating into neurons and glia that will form the new tissue. Interestingly, these cells have the potential to either evade immune recognition or to locally modulate an immune response. Embryonic stem cells are less susceptible to immune rejection than adult cells due to an absence of major histocompatibility complex (MHC)-II and CD80/CD86, and very low levels of MHC-I expression [Drukker et al., 2002; Drukker, 2006]; however, these cells cannot confer this tolerance to local cells through the secretion of anti-inflammatory cytokines. Within neural stem cell (NSC) populations, the presentation of MHC molecules is variable due to the isolation source and the inflammatory milieu, suggesting subpopulations of NSCs offer an improved survival capacity [Bonnamain et al., 2012b]. These cells that survive, along with endogenous NSCs in the spinal cord, have the ability to modulate the local immune response, such as macrophage polarization and T cell phenotype after SCI - a characteristic shared with mesenchymal stem cells (MSCs) [Wang et al., 2009; Bonnamain et al., 2012a; English, 2013; Barbeau et al., 2014; Gao et al., 2014; Yan et al., 2014].

MSCs and NSCs modulate the immune cells through numerous mechanisms, including direct cell-cell contact and indirect contact via cytokines and signaling molecules [Wang et al., 2009; Bonnamain et al., 2012a; English, 2013; Luz-Crawford et al., 2013; Barbeau et al., 2014; Gao et al., 2014; Nazmi et al., 2014; Obermajer et al., 2014; Yan et al., 2014]. NSCs release soluble factors such as TGF- $\beta 1$, prostaglandin E, nitric oxide, and hemeoxygenase- 1 that increase regulatory $\mathrm{T}$ cell populations at the expense of effector T cells [Wang et al., 2009; Bonnamain et al., 2012a; Nazmi et al., 2014]. NSCs can also effect these changes directly through contact with $\mathrm{T}$ cell populations using intracellular adhesion molecules and B7 cell surface proteins [Nazmi et al., 2014]. Through direct contact and local cytokine release, NSCs promoted an increase in regulatory $\mathrm{T}$ cells, increased the expression of anti-inflammatory cytokines and decreased proinflammatory cytokines [Gao et al., 2014]. Similarly, MSCs injected into a contused spinal cord reduced macrophage infiltration, restored the blood spinal cord barrier, led to the alternative polarization of macrophages and microglia, and improved hind limb motor function [Watanabe et al., 2015].
A decrease in the proinflammatory cytokines (TNF- $\alpha$, IL6), mediators of vascular permeability (MMP-9), macrophage recruitment factors CCL-2 and CCL-5, and chemokine $\mathrm{C}-\mathrm{X}-\mathrm{C}$ ligand 10 , coupled with an increase in GM-CSF within the first $24 \mathrm{~h}$ after SCI likely contributed to the improved functional outcomes [Watanabe et al., 2015].

\section{Conclusions and Future Directions}

Substantial strides have been made in individual approaches to immunomodulation after SCI, but these approaches only have the capacity to indirectly promote regeneration. Individually, these approaches effect changes at a specific time point or through a target cell population within the inflammatory cascade, as demonstrated in figure 1. Each of these treatments has demonstrated modest effects on its own, but small improvements in rodent sensorimotor function do not correspond to clinically significant improvements in quality of life. Future therapies will need to investigate how biomaterials, biologically active molecules, gene therapy, nanoparticles, and/or cell transplants can be used in concert to directly promote regeneration while mitigating inflammation without impairing wound healing and the closing of the blood-brain barrier. Combination therapies will require further investigation as to the mechanism by which these therapies modulate the immune system to optimize their efficacy; however, in combination, these therapies may have additive or synergistic effects on regeneration that may transform the field.

\section{Acknowledgements}

Funding was provided by the National Institutes of Health (RO1EB005678).

\section{Disclosure Statement}

The authors declare no competing interests.
Dumont/Margul/Shea 


\section{References}

-Almeida, C.R., T. Serra, M.I. Oliveira, J.A. Planell, M.A. Barbosa, M. Navarro (2014) Impact of 3-D printed PLA- and chitosan-based scaffolds on human monocyte/macrophage responses: unraveling the effect of 3-D structures on inflammation. Acta Biomater 10: 613-622.

-Aloisi, F., A. Care, G. Borsellino, P. Gallo, S. Rosa, A. Bassani, A. Cabibbo, U. Testa, G. Levi, C. Peschle (1992) Production of hemolymphopoietic cytokines (IL-6, IL-8, colony-stimulating factors) by normal human astrocytes in response to IL-1 beta and tumor necrosis factor-alpha. J Immunol 149: 2358-2366.

Bao, F., G.A. Dekaban, L.C. Weaver (2005) AntiCD11d antibody treatment reduces free radical formation and cell death in the injured spinal cord of rats. J Neurochem 94: 1361-1373.

Barbeau, D.J., K.T. La, D.S. Kim, S.S. Kerpedjieva, G.V. Shurin, K. Tamama (2014) Early growth response-2 signaling mediates immunomodulatory effects of human multipotential stromal cells. Stem Cells Dev 23: 155-166.

Bartus, K., N.D. James, A. Didangelos, K.D. Bosch, J. Verhaagen, R.J. Yanez-Munoz, J.H. Rogers, B.L. Schneider, E.M. Muir, E.J. Bradbury (2014) Large-scale chondroitin sulfate proteoglycan digestion with chondroitinase gene therapy leads to reduced pathology and modulates macrophage phenotype following spinal cord contusion injury. J Neurosci 34: 4822-4836.

Beck, K.D., H.X. Nguyen, M.D. Galvan, D.L. Salazar, T.M. Woodruff, A.J. Anderson (2010) Quantitative analysis of cellular inflammation after traumatic spinal cord injury: evidence for a multiphasic inflammatory response in the acute to chronic environment. Brain 133: 433-447.

Belkas, J.S., C.A. Munro, M.S. Shoichet, M. Johnston, R. Midha (2005) Long-term in vivo biomechanical properties and biocompatibility of poly(2-hydroxyethyl methacrylate-comethyl methacrylate) nerve conduits. Biomaterials 26: 1741-1749.

Benkhoucha, M., M.L. Santiago-Raber, G. Schneiter, M. Chofflon, H. Funakoshi, T. Nakamura, P.H. Lalive (2010) Hepatocyte growth factor inhibits CNS autoimmunity by inducing tolerogenic dendritic cells and CD25+Foxp3+ regulatory T cells. Proc Natl Acad Sci USA 107: 6424-6429.

Bethea, J.R., H. Nagashima, M.C. Acosta, C. Briceno, F. Gomez, A.E. Marcillo, K. Loor, J. Green, W.D. Dietrich (1999) Systemically administered interleukin-10 reduces tumor necrosis factor-alpha production and significantly improves functional recovery following traumatic spinal cord injury in rats. J Neurotrauma 16: 851-863.

Bhalala, O.G., L. Pan, V. Sahni, T.L. McGuire, K. Gruner, W.G. Tourtellotte, J.A. Kessler (2012) microRNA-21 regulates astrocytic response following spinal cord injury. J Neurosci 32: 17935-17947.
Blakney, A.K., M.D. Swartzlander, S.J. Bryant (2012) The effects of substrate stiffness on the in vitro activation of macrophages and in vivo host response to poly(ethylene glycol)-based hydrogels. J Biomed Mater Res A 100: 13751386.

Blits, B., M.B. Bunge (2006) Direct gene therapy for repair of the spinal cord. J Neurotrauma 23: 508-520.

Boehler, R.M., R. Kuo, S. Shin, A.G. Goodman, M.A. Pilecki, R.M. Gower, J.N. Leonard, L.D. Shea (2014) Lentivirus delivery of IL-10 to promote and sustain macrophage polarization towards an anti-inflammatory phenotype. Biotechnol Bioeng 111: 1210-1221.

Bonnamain, V., E. Mathieux, R. Thinard, P. Thebault, V. Nerriere-Daguin, X. Leveque, I. Anegon, B. Vanhove, I. Neveu, P. Naveilhan (2012a) Expression of heme oxygenase-1 in neural stem/progenitor cells as a potential mechanism to evade host immune response. Stem Cells 30: 2342-2353.

Bonnamain, V., I. Neveu, P. Naveilhan (2012b) Neural stem/progenitor cells as a promising candidate for regenerative therapy of the central nervous system. Front Cell Neurosci 6: 17.

Boulis, N.M., V. Bhatia, T.I. Brindle, H.T. Holman, D.J. Krauss, M. Blaivas, J.T. Hoff (1999) Adenoviral nerve growth factor and beta-galactosidase transfer to spinal cord: a behavioral and histological analysis. J Neurosurg 90(1 suppl): 99-108.

Busch, S.A., K.P. Horn, D.J. Silver, J. Silver (2009) Overcoming macrophage-mediated axonal dieback following CNS injury. J Neurosci 29: 9967-9976.

Busch, S.A., J. Silver (2007) The role of extracellular matrix in CNS regeneration. Curr Opin Neurobiol 17: 120-127.

Cao, H., K. McHugh, S.Y. Chew, J.M. Anderson (2010) The topographical effect of electrospun nanofibrous scaffolds on the in vivo and in vitro foreign body reaction. J Biomed $\mathrm{Ma}-$ ter Res A 93: 1151-1159.

Chu, H., Y. Tang, Q. Dong (2014) Protection of granulocyte-colony stimulating factor to hemorrhagic brain injuries and its involved mechanisms: effects of vascular endothelial growth factor and aquaporin-4. Neuroscience 260: 59-72.

Chung, J., M.H. Kim, Y.J. Yoon, K.H. Kim, S.R. Park, B.H. Choi (2014) Effects of granulocyte colony-stimulating factor and granulocytemacrophage colony-stimulating factor on glial scar formation after spinal cord injury in rats. J Neurosurg Spine 21: 966-973.

Cote, M.P., A.A. Amin, V.J. Tom, J.D. Houle (2011) Peripheral nerve grafts support regeneration after spinal cord injury. Neurotherapeutics 8: 294-303.

Cregg, J.M., M.A. DePaul, A.R. Filous, B.T. Lang, A. Tran, J. Silver (2014) Functional regeneration beyond the glial scar. Exp Neurol 253: 197-207.
Dadsetan, M., T.E. Hefferan, J.P. Szatkowski, P.K. Mishra, S.I. Macura, L. Lu, M.J. Yaszemski (2008) Effect of hydrogel porosity on marrow stromal cell phenotypic expression. Biomaterials 29: 2193-2202.

- David, S., A.J. Aguayo (1981) Axonal elongation into peripheral nervous system 'bridges' after central nervous system injury in adult rats. Science 214: 931-933.

De Laporte, L., A.L. Yan, L.D. Shea (2009a) Local gene delivery from ECM-coated poly(lactideco-glycolide) multiple channel bridges after spinal cord injury. Biomaterials 30: 23612368.

De Laporte, L., Y. Yang, M.L. Zelivyanskaya, B.J. Cummings, A.J. Anderson, L.D. Shea (2009b) Plasmid releasing multiple channel bridges for transgene expression after spinal cord injury. Mol Ther 17: 318-326.

Didangelos, A., M. Iberl, E. Vinsland, K. Bartus, E.J. Bradbury (2014) Regulation of IL-10 by chondroitinase $\mathrm{ABC}$ promotes a distinct immune response following spinal cord injury. J Neurosci 34: 16424-16432.

Donnelly, D.J., P.G. Popovich (2008) Inflammation and its role in neuroprotection, axonal regeneration and functional recovery after spinal cord injury. Exp Neurol 209: 378388 .

Drukker, M. (2006) Immunogenicity of embryonic stem cells and their progeny. Methods Enzymol 420: 391-409.

Drukker, M., G. Katz, A. Urbach, M. Schuldiner, G. Markel, J. Itskovitz-Eldor, B. Reubinoff, O. Mandelboim, N. Benvenisty (2002) Characterization of the expression of MHC proteins in human embryonic stem cells. Proc Natl Acad Sci USA 99: 9864-9869.

English, K. (2013) Mechanisms of mesenchymal stromal cell immunomodulation. Immunol Cell Biol 91: 19-26.

Fenn, A.M., J.C. Hall, J.C. Gensel, P.G. Popovich, J.P. Godbout (2014) IL-4 signaling drives a unique arginase $+/$ IL- $1 \beta+$ microglia phenotype and recruits macrophages to the inflammatory CNS: consequences of age-related deficits in IL-4Ra after traumatic spinal cord injury. J Neurosci 34: 8904-8917.

Filbin, M.T. (2003) Myelin-associated inhibitors of axonal regeneration in the adult mammalian CNS. Nat Rev Neurosci 4: 703-713.

Fitch, M.T., C. Doller, C.K. Combs, G.E. Landreth, J. Silver (1999) Cellular and molecular mechanisms of glial scarring and progressive cavitation: in vivo and in vitro analysis of inflammation-induced secondary injury after CNS trauma. J Neurosci 19: 8182-8198.

Gao, L., Q. Lu, L.J. Huang, L.H. Ruan, J.J. Yang, W.L. Huang, W.S. ZhuGe, Y.L. Zhang, B. Fu, K.L. Jin, Q.C. ZhuGe (2014) Transplanted neural stem cells modulate regulatory $\mathrm{T}, \gamma \delta \mathrm{T}$ cells and corresponding cytokines after intracerebral hemorrhage in rats. Int J Mol Sci 15 : 4431-4441. 
Gaudet, A.D., D.R. Sweet, N.K. Polinski, Z. Guan, P.G. Popovich (2015) Galectin-1 in injured rat spinal cord: implications for macrophage phagocytosis and neural repair. Mol Cell Neurosci 64: 84-94.

Geremia, N.M., F. Bao, T.E. Rosenzweig, T. Hryciw, L. Weaver, G.A. Dekaban, A. Brown (2012) CD11d antibody treatment improves recovery in spinal cord-injured mice. J Neurotrauma 29: 539-550.

Getts, D.R., A.J. Martin, D.P. McCarthy, R.L. Terry, Z.H. Hunter, W.T. Yap, M.T. Getts, M. Pleiss, X. Luo, N.J.C. King, L.D. Shea, S.D. Miller (2012) Microparticles bearing encephalitogenic peptides induce T-cell tolerance and ameliorate experimental autoimmune encephalomyelitis. Nat Biotechnol 30: 1217-1224.

Guo, Y., H. Zhang, J. Yang, S. Liu, L. Bing, J. Gao, A. Hao (2013) Granulocyte colony-stimulating factor improves alternative activation of microglia under microenvironment of spinal cord injury. Neuroscience 238: 1-10.

-Haggerty, A.E., M. Oudega (2013) Biomaterials for spinal cord repair. Neurosci Bull 29: 445459.

Hamilton, T.A., C. Zhao, P.G. Pavicic Jr., S. Datta (2014) Myeloid colony-stimulating factors as regulators of macrophage polarization. Front Immunol 5: 554.

Hao, S., M. Mata, J.C. Glorioso, D.J. Fink (2006) HSV-mediated expression of interleukin-4 in dorsal root ganglion neurons reduces neuropathic pain. Mol Pain 2: 6 .

-Hayashi, K., S. Ohta, Y. Kawakami, M. Toda (2009) Activation of dendritic-like cells and neural stem/progenitor cells in injured spinal cord by GM-CSF. Neurosci Res 64: 96-103.

-Hejcl, A., L. Urdzikova, J. Sedy, P. Lesny, M. Pradny, J. Michalek, M. Burian, M. Hajek, J. Zamecnik, P. Jendelova, E. Sykova (2008) Acute and delayed implantation of positively charged 2-hydroxyethyl methacrylate scaffolds in spinal cord injury in the rat. J Neurosurg Spine 8: 67-73.

Hezi-Yamit, A., C. Sullivan, J. Wong, L. David, M. Chen, P. Cheng, D. Shumaker, J.N. Wilcox, K. Udipi (2009) Impact of polymer hydrophilicity on biocompatibility: implication for DES polymer design. J Biomed Mater Res A 90: 133-141.

Horn, K.P., S.A. Busch, A.L. Hawthorne, N. van Rooijen, J. Silver (2008) Another barrier to regeneration in the CNS: activated macrophages induce extensive retraction of dystrophic axons through direct physical interactions. J Neurosci 28: 9330-9341.

-Hume, P.S., K.S. Anseth (2010) Inducing local T cell apoptosis with anti-Fas-functionalized polymeric coatings fabricated via surface-initiated photopolymerizations. Biomaterials 31: 3166-3174.

Hunter, Z., D.P. McCarthy, W.T. Yap, C.T. Harp, D.R. Getts, L.D. Shea, S.D. Miller (2014) A biodegradable nanoparticle platform for the induction of antigen-specific immune tolerance for treatment of autoimmune disease. ACS Nano 8: 2148-2160.
Hutter, E., S. Boridy, S. Labrecque, M. LalancetteHebert, J. Kriz, F.M. Winnik, D. Maysinger (2010) Microglial response to gold nanoparticles. ACS Nano 4: 2595-2606.

-Ifergan, I., K. Wosik, R. Cayrol, H. Kebir, C. Auger, M. Bernard, A. Bouthillier, R. Moumdjian, P. Duquette, A. Prat (2006) Statins reduce human blood-brain barrier permeability and restrict leukocyte migration: relevance to multiple sclerosis. Ann Neurol 60: 45-55.

Ilinskaya, A.N., M.A. Dobrovolskaia (2014) Immunosuppressive and anti-inflammatory properties of engineered nanomaterials. $\mathrm{Br} \mathrm{J}$ Pharmacol 171: 3988-4000.

-Jackson, C.A., J. Messinger, J.D. Peduzzi, D.C. Ansardi, C.D. Morrow (2005) Enhanced functional recovery from spinal cord injury following intrathecal or intramuscular administration of poliovirus replicons encoding IL-10. Virology 336: 173-183.

Jeffery, N.D., S.C. McBain, J. Dobson, D.M. Chari (2009) Uptake of systemically administered magnetic nanoparticles (MNPs) in areas of experimental spinal cord injury (SCI). J Tissue Eng Regen Med 3: 153-157.

Jeong, S.R., M.J. Kwon, H.G. Lee, E.H. Joe, J.H. Lee, S.S. Kim, H. Suh-Kim, B.G. Kim (2012) Hepatocyte growth factor reduces astrocytic scar formation and promotes axonal growth beyond glial scars after spinal cord injury. Exp Neurol 233: 312-322.

Ji, X.C., Y.Y. Dang, H.Y. Gao, Z.T. Wang, M. Gao, Y. Yang, H.T. Zhang, R.X. Xu (2015) Local injection of Lenti-BDNF at the lesion site promotes M2 macrophage polarization and inhibits inflammatory response after spinal cord injury in mice. Cell Mol Neurobiol 35: 881-890.

Jones, J.A., D.T. Chang, H. Meyerson, E. Colton, I.K. Kwon, T. Matsuda, J.M. Anderson (2007) Proteomic analysis and quantification of cytokines and chemokines from biomaterial surface-adherent macrophages and foreign body giant cells. J Biomed Mater Res A 83: 585-596.

-Jones, L.L., M.H. Tuszynski (2001) Chronic intrathecal infusions after spinal cord injury cause scarring and compression. Microsc Res Tech 54: $317-324$.

-Jones, T.B. (2014) Lymphocytes and autoimmunity after spinal cord injury. Exp Neurol 258: 78-90.

Kang, C.E., P.C. Poon, C.H. Tator, M.S. Shoichet (2009) A new paradigm for local and sustained release of therapeutic molecules to the injured spinal cord for neuroprotection and tissue repair. Tissue Eng Part A 15: 595-604.

Kanno, S., A. Furuyama, S. Hirano (2007) A murine scavenger receptor MARCO recognizes polystyrene nanoparticles. Toxicol Sci 97: 398-406.

Khaing, Z.Z., B.D. Milman, J.E. Vanscoy, S.K. Seidlits, R.J. Grill, C.E. Schmidt (2011) High molecular weight hyaluronic acid limits astrocyte activation and scar formation after spinal cord injury. J Neural Eng 8: 046033.
Kigerl, K.A., J.C. Gensel, D.P. Ankeny, J.K. Alexander, D.J. Donnelly, P.G. Popovich (2009) Identification of two distinct macrophage subsets with divergent effects causing either neurotoxicity or regeneration in the injured mouse spinal cord. J Neurosci 29: 1343513444.

Kim, S.H., N. Bianco, R. Menon, E.R. Lechman, W.J. Shufesky, A.E. Morelli, P.D. Robbins (2006) Exosomes derived from genetically modified DC expressing FasL are anti-inflammatory and immunosuppressive. Mol Ther 13: 289-300.

Kitayama, M., M. Ueno, T. Itakura, T. Yamashita (2011) Activated microglia inhibit axonal growth through RGMa. PLoS One 6: e25234.

Klusman, I., M.E. Schwab (1997) Effects of proinflammatory cytokines in experimental spinal cord injury. Brain Res 762: 173-184.

Kuo, H.S., M.J. Tsai, M.C. Huang, C.W. Chiu, C.Y. Tsai, M.J. Lee, W.C. Huang, Y.L. Lin, W.C. Kuo, H. Cheng (2011) Acid fibroblast growth factor and peripheral nerve grafts regulate Th2 cytokine expression, macrophage activation, polyamine synthesis, and neurotrophin expression in transected rat spinal cords. J Neurosci 31: 4137-4147.

Kwon, K.W., H. Park, K.H. Song, J.C. Choi, H. Ahn, M.J. Park, K.Y. Suh, J. Doh (2012) Nanotopography-guided migration of T cells. J Immunol 189: 2266-2273.

Lee, S., J. Choi, S. Shin, Y.M. Im, J. Song, S.S Kang, T.H. Nam, T.J. Webster, S.H. Kim, D. Khang (2011) Analysis on migration and activation of live macrophages on transparent flat and nanostructured titanium. Acta Biomater 7: 2337-2344.

Lee, S.I., S.R. Jeong, Y.M. Kang, D.H. Han, B.K. Jin, U. Namgung, B.G. Kim (2010) Endogenous expression of interleukin-4 regulates macrophage activation and confines cavity formation after traumatic spinal cord injury. J Neurosci Res 88: 2409-2419.

Lee, S.R., H.Y. Kim, J.S. Hong, W.K. Baek, J.W Park (2009) PPAR $\gamma$ agonist pioglitazone reduces matrix metalloproteinase- 9 activity and neuronal damage after focal cerebral ischemia. Biochem Biophys Res Commun 380: $17-21$.

Li, X., X. Liu, W. Zhao, X. Wen, N. Zhang (2012) Manipulating neural-stem-cell mobilization and migration in vitro. Acta Biomater 8: 2087-2095.

Luo, J., R. Shi (2007) Polyethylene glycol inhibits apoptotic cell death following traumatic spinal cord injury. Brain Res 1155: 10-16.

Luz-Crawford, P., M. Kurte, J. Bravo-Alegria, R. Contreras, E. Nova-Lamperti, G. Tejedor, D. Noel, C. Jorgensen, F. Figueroa, F. Djouad, F. Carrion (2013) Mesenchymal stem cells generate a CD4+CD25+Foxp3+ regulatory T cell population during the differentiation process of Th1 and Th17 cells. Stem Cell Res Ther 4: 65. 
Maldonado, R.A., R.A. LaMothe, J.D. Ferrari, A.H. Zhang, R.J. Rossi, P.N. Kolte, A.P. Griset, C. O'Neil, D.H. Altreuter, E. Browning, L. Johnston, O.C. Farokhzad, R. Langer, D.W. Scott, U.H. von Andrian, T.K. Kishimoto (2015) Polymeric synthetic nanoparticles for the induction of antigen-specific immunological tolerance. Proc Natl Acad Sci USA 112: E156-E165.

Martinez, F.O., A. Sica, A. Mantovani, M. Locati (2008) Macrophage activation and polarization. Front Biosci 13: 453-461.

McWhorter, F.Y., T. Wang, P. Nguyen, T. Chung, W.F. Liu (2013) Modulation of macrophage phenotype by cell shape. Proc Natl Acad Sci USA 110: 17253-17258.

Merino, J.J., V. Bellver-Landete, M.J. OsetGasque, B. Cubelos (2015) CXCR4/CXCR7 molecular involvement in neuronal and neural progenitor migration: focus in CNS repair. J Cell Physiol 230: 27-42.

Minami, S.S., B. Sun, K. Popat, T. Kauppinen, M. Pleiss, Y. Zhou, M.E. Ward, P. Floreancig, L. Mucke, T. Desai, L. Gan (2012) Selective targeting of microglia by quantum dots. J Neuroinflammation 9: 22 .

-Moquin, A., K.D. Neibert, D. Maysinger, F.M. Winnik (2015) Quantum dot agglomerates in biological media and their characterization by asymmetrical flow field-flow fractionation. Eur J Pharm Biopharm 89: 290-299.

Mosser, D.M. (2003) The many faces of macrophage activation. J Leukoc Biol 73: 209-212.

Murray, P.J., T.A. Wynn (2011) Protective and pathogenic functions of macrophage subsets. Nat Rev Immunol 11: 723-737.

Nayak, S., R.W. Herzog (2010) Progress and prospects: immune responses to viral vectors. Gene Ther 17: 295-304.

Nazmi, A., I. Mohamed Arif, K. Dutta, K. Kundu, A. Basu (2014) Neural stem/progenitor cells induce conversion of encephalitogenic T cells into $\mathrm{CD}^{+}-\mathrm{CD} 25^{+}-\mathrm{FOXP}^{+}$regulatory $\mathrm{T}$ cells. Viral Immunol 27: 48-59.

Noble, L.J., F. Donovan, T. Igarashi, S. Goussev, Z. Werb (2002) Matrix metalloproteinases limit functional recovery after spinal cord injury by modulation of early vascular events. J Neurosci 22: 7526-7535.

- Obermajer, N., F.C. Popp, Y. Soeder, J. Haarer, E.K. Geissler, H.J. Schlitt, M.H. Dahlke (2014) Conversion of Th17 into IL-17 $\mathrm{A}^{\text {neg }}$ regulatory $\mathrm{T}$ cells: a novel mechanism in prolonged allograft survival promoted by mesenchymal stem cell-supported minimized immunosuppressive therapy. J Immunol 193: 4988-4999.

Olson, H.E., G.E. Rooney, L. Gross, J.J. Nesbitt, K.E. Galvin, A. Knight, B. Chen, M.J. Yaszemski, A.J. Windebank (2009) Neural stem celland Schwann cell-loaded biodegradable polymer scaffolds support axonal regeneration in the transected spinal cord. Tissue Eng Part A 15: 1797-1805.
Pal, A., A. Singh, T.C. Nag, P. Chattopadhyay, R. Mathur, S. Jain (2013) Iron oxide nanoparticles and magnetic field exposure promote functional recovery by attenuating free radical-induced damage in rats with spinal cord transection. Int J Nanomedicine 8: 2259-2272.

Papa, S., R. Ferrari, M. De Paola, F. Rossi, A. Mariani, I. Caron, E. Sammali, M. Peviani, V. Dell'Oro, C. Colombo, M. Morbidelli, G. Forloni, G. Perale, D. Moscatelli, P. Veglianese (2014) Polymeric nanoparticle system to target activated microglia/macrophages in spinal cord injury. J Control Release 174: 15-26.

Papa, S., F. Rossi, R. Ferrari, A. Mariani, M. De Paola, I. Caron, F. Fiordaliso, C. Bisighini, E. Sammali, C. Colombo, M. Gobbi, M. Canovi, J. Lucchetti, M. Peviani, M. Morbidelli, G. Forloni, G. Perale, D. Moscatelli, P. Veglianese (2013) Selective nanovector mediated treatment of activated proinflammatory microglia/macrophages in spinal cord injury. ACS Nano 7: 9881-9895.

-Pearl-Yafe, M., E.S. Yolcu, J. Stein, O. Kaplan, I. Yaniv, H. Shirwan, N. Askenasy (2007) Fas ligand enhances hematopoietic cell engraftment through abrogation of alloimmune responses and nonimmunogenic interactions. Stem Cells 25: 1448-1455.

Pomeshchik, Y., I. Kidin, P. Korhonen, E. Savchenko, M. Jaronen, S. Lehtonen, S. Wojciechowski, K. Kanninen, J. Koistinaho, T. Malm (2015) Interleukin-33 treatment reduces secondary injury and improves functional recovery after contusion spinal cord injury. Brain Behav Immun 44: 68-81.

Popovich, P.G., Z. Guan, V. McGaughy, L. Fisher, W.F. Hickey, D.M. Basso (2002) The neuropathological and behavioral consequences of intraspinal microglial/macrophage activation. J Neuropathol Exp Neurol 61: 623-633.

Popovich, P.G., Z. Guan, P. Wei, I. Huitinga, N. van Rooijen, B.T. Stokes (1999) Depletion of hematogenous macrophages promotes partial hindlimb recovery and neuroanatomical repair after experimental spinal cord injury. Exp Neurol 158: 351-365.

Popovich, P.G., P.J. Horner, B.B. Mullin, B.T. Stokes (1996) A quantitative spatial analysis of the blood-spinal cord barrier. I. Permeability changes after experimental spinal contusion injury. Exp Neurol 142: 258-275.

Pruss, H., M.A. Kopp, B. Brommer, N. Gatzemeier, I. Laginha, U. Dirnagl, J.M. Schwab (2011) Non-resolving aspects of acute inflammation after spinal cord injury (SCI): indices and resolution plateau. Brain Pathol 21: 652-660.

Ruoslahti, E. (2012) Peptides as targeting elements and tissue penetration devices for nanoparticles. Adv Mater 24: 3747-3756.

Saino, E., M.L. Focarete, C. Gualandi, E. Emanuele, A.I. Cornaglia, M. Imbriani, L. Visai (2011) Effect of electrospun fiber diameter and alignment on macrophage activation and secretion of proinflammatory cytokines and chemokines. Biomacromolecules 12: 19001911.
Sakiyama-Elbert, S., P.J. Johnson, S.I. Hodgetts, G.W. Plant, A.R. Harvey (2012) Scaffolds to promote spinal cord regeneration. Handb Clin Neurol 109: 575-594.

Saville, L.R., C.H. Pospisil, L.A. Mawhinney, F. Bao, F.C. Simedrea, A.A. Peters, P.J. O'Connell, L.C. Weaver, G.A. Dekaban (2004) A monoclonal antibody to CD11d reduces the inflammatory infiltrate into the injured spinal cord: a potential neuroprotective treatment. J Neuroimmunol 156: 42-57.

- Shechter, R., A. London, C. Varol, C. Raposo, M. Cusimano, G. Yovel, A. Rolls, M. Mack, S. Pluchino, G. Martino, S. Jung, M. Schwartz (2009) Infiltrating blood-derived macrophages are vital cells playing an anti-inflammatory role in recovery from spinal cord injury in mice. PLoS Med 6: e1000113.

-Sindrilaru, A., T. Peters, S. Wieschalka, C. Baican, A. Baican, H. Peter, A. Hainzl, S. Schatz, Y. Qi, A. Schlecht, J.M. Weiss, M. Wlaschek, C. Sunderkotter, K. Scharffetter-Kochanek (2011) An unrestrained proinflammatory M1 macrophage population induced by iron impairs wound healing in humans and mice. J Clin Invest 121: 985-997.

-Sroga, J.M., T.B. Jones, K.A. Kigerl, V.M. McGaughy, P.G. Popovich (2003) Rats and mice exhibit distinct inflammatory reactions after spinal cord injury. J Comp Neurol 462: 223240.

Stirling, D.P., S. Liu, P. Kubes, V.W. Yong (2009) Depletion of Ly6G/Gr-1 leukocytes after spinal cord injury in mice alters wound healing and worsens neurological outcome. J Neurosci 29: 753-764.

Straley, K.S., C.W. Foo, S.C. Heilshorn (2010) Biomaterial design strategies for the treatment of spinal cord injuries. J Neurotrauma 27: 1-19.

- Surey, S., M. Berry, A. Logan, R. Bicknell, Z. Ahmed (2014) Differential cavitation, angiogenesis and wound-healing responses in injured mouse and rat spinal cords. Neuroscience 275: 62-80.

Sussman, E.M., M.C. Halpin, J. Muster, R.T. Moon, B.D. Ratner (2014) Porous implants modulate healing and induce shifts in local macrophage polarization in the foreign body reaction. Ann Biomed Eng 42: 1508-1516.

Taylor, S.J., E.S. Rosenzweig, J.W. McDonald 3rd S.E. Sakiyama-Elbert (2006) Delivery of neurotrophin-3 from fibrin enhances neuronal fiber sprouting after spinal cord injury. J Control Release 113: 226-235.

Teng, Y.D., E.B. Lavik, X. Qu, K.I. Park, J. Ourednik, D. Zurakowski, R. Langer, E.Y. Snyder (2002) Functional recovery following traumatic spinal cord injury mediated by a unique polymer scaffold seeded with neural stem cells. Proc Natl Acad Sci USA 99: 3024-3029.

Thomas, A.M., M.B. Kubilius, S.J. Holland, S.K. Seidlits, R.M. Boehler, A.J. Anderson, B.J. Cummings, L.D. Shea (2013) Channel density and porosity of degradable bridging scaffolds on axon growth after spinal injury. Biomaterials 34: $2213-2220$. 
Thomas, A.M., L.D. Shea (2013) Polysaccharidemodified scaffolds for controlled lentivirus delivery in vitro and after spinal cord injury. J Control Release 170: 421-429.

-Tuinstra, H.M., D.J. Margul, A.G. Goodman, R.M. Boehler, S.J. Holland, M.L. Zelivyanskaya, B.J. Cummings, A.J. Anderson, L.D. Shea (2014) Long-term characterization of axon regeneration and matrix changes using multiple channel bridges for spinal cord regeneration. Tissue Eng Part A 20: 1027 1037.

Vannier, E., L.C. Miller, C.A. Dinarello (1992) Coordinated antiinflammatory effects of interleukin 4: interleukin 4 suppresses interleukin 1 production but up-regulates gene expression and synthesis of interleukin 1 receptor antagonist. Proc Natl Acad Sci USA 89: 4076-4080.

-Walthers, C.M., S.K. Seidlits (2015) Gene delivery strategies to promote spinal cord repair. Biomark Insights 10(suppl 1): 11-29.

Wang, C.Y., S.H. Yang, S.F. Tzeng (2015) MicroRNA-145 as one negative regulator of astrogliosis. Glia 63: 194-205.

-Wang, L., J. Shi, F.W. van Ginkel, L. Lan, G. Niemeyer, D.R. Martin, E.Y. Snyder, N.R. Cox (2009) Neural stem/progenitor cells modulate immune responses by suppressing $\mathrm{T}$ lymphocytes with nitric oxide and prostaglandin E2. Exp Neurol 216: 177-183.

Watanabe, S., K. Uchida, H. Nakajima, H. Matsuo, D. Sugita, A. Yoshida, K. Honjoh, W.E.
Johnson, H. Baba (2015) Early transplantation of mesenchymal stem cells after spinal cord injury relieves pain hypersensitivity through suppression of pain-related signaling cascades and reduced inflammatory cell recruitment. Stem Cells 33: 1902-1914.

Waxman, S.G. (1989) Demyelination in spinal cord injury. J Neurol Sci 91: 1-14.

Weidner, N., M.H. Tuszynski (2002) Spontaneous plasticity in the injured spinal cord-implications for repair strategies. Mol Psychiatry 7: 9-11.

Whetstone, W.D., J.Y. Hsu, M. Eisenberg, Z. Werb, L.J. Noble-Haeusslein (2003) Bloodspinal cord barrier after spinal cord injury: relation to revascularization and wound healing. J Neurosci Res 74: 227-239.

Wilems, T.S., S.E. Sakiyama-Elbert (2015) Sustained dual drug delivery of anti-inhibitory molecules for treatment of spinal cord injury. J Control Release 213: 103-111.

Wong, D.Y., J.C. Leveque, H. Brumblay, P.H. Krebsbach, S.J. Hollister, F. Lamarca (2008) Macro-architectures in spinal cord scaffold implants influence regeneration. J Neurotrauma 25: 1027-1037.

Yan, Z., Y. Zhuansun, R. Chen, J. Li, P. Ran (2014) Immunomodulation of mesenchymal stromal cells on regulatory $\mathrm{T}$ cells and its possible mechanism. Exp Cell Res 324: 65-74.

-Yang, Y., L. De Laporte, M.L. Zelivyanskaya, K.J. Whittlesey, A.J. Anderson, B.J. Cummings, L.D. Shea (2009) Multiple channel bridges for spinal cord injury: cellular characterization of host response. Tissue Eng Part A 15: 32833295.

Yasuoka, S., J. Kawanokuchi, B. Parajuli, S. Jin, Y. Doi, M. Noda, Y. Sonobe, H. Takeuchi, T. Mizuno, A. Suzumura (2011) Production and functions of IL-33 in the central nervous system. Brain Res 1385: 8-17.

Yiu, G., Z. He (2006) Glial inhibition of CNS axon regeneration. Nat Rev Neurosci 7: 617-627.

Yuan, R., Y. Maeda, W. Li, W. Lu, S. Cook, P. Dowling (2008) Erythropoietin: a potent inducer of peripheral immuno/inflammatory modulation in autoimmune EAE. PLoS One 3: e1924.

Zhou, Z., X. Peng, R. Insolera, D.J. Fink, M. Mata (2009a) IL-10 promotes neuronal survival following spinal cord injury. Exp Neurol 220: 183-190.

Zhou, Z., X. Peng, R. Insolera, D.J. Fink, M. Mata (2009b) Interleukin-10 provides direct trophic support to neurons. J Neurochem 110: $1617-1627$.

Zuidema, J.M., R.J. Gilbert, D.J. Osterhout (2016) Nanoparticle technologies in the spinal cord. Cells Tissues Organs 202: 102-115.

Zuidema, J.M., M.C. Hyzinski-Garcia, K. Van Vlasselaer, N.W. Zaccor, G.E. Plopper, A.A. Mongin, R.J. Gilbert (2014) Enhanced GLT-1 mediated glutamate uptake and migration of primary astrocytes directed by fibronectincoated electrospun poly-L-lactic acid fibers. Biomaterials 35: 1439-1449. 